\title{
Resistance of melanized yeast cells of Paracoccidioides brasiliensis to antimicrobial oxidants and inhibition of phagocytosis using carbohydrates and monoclonal antibody to CD18
}

\author{
Marcelo Barbosa da Silva1, Luciana Thomaz', Alexandre Ferreira Marques' ${ }^{1}$, Artur E Svidzinski ${ }^{1}$, \\ Josh D Nosanchuk ${ }^{2}$, Arturo Casadevall ${ }^{2}$, Luiz R Travassos ${ }^{3}$, Carlos P Taborda ${ }^{1 /+}$ \\ ${ }^{1}$ Instituto de Ciências Biomédicas, Departamento de Microbiologia, Laboratório de Micologia Médica - LIM53 - Hospital de Clínicas, \\ Faculdade de Medicina, Universidade de São Paulo, São Paulo, SP, Brasil ${ }^{2}$ Departments of Medicine and Microbiology and Immunol- \\ ogy, Albert Einstein College of Medicine, New York, NY, USA ${ }^{3}$ Departamento de Microbiologia, Imunologia e Parasitologia, Universidade \\ Federal de São Paulo, São Paulo, SP, Brasil
}

Paracoccidioides brasiliensis, a thermal dimorphic fungal pathogen, produces a melanin-like pigment in vitro and in vivo. We investigated the involvement of carbohydrates and monoclonal antibody to CD18, on phagocytosis inhibition, involving macrophage receptors and the resistance of melanized fungal cells to chemically generated nitric oxide (NO), reactive oxygen species (ROS), hypochlorite and $\mathrm{H}_{2} \mathrm{O}_{2}$. Our results demonstrate that melanized yeast cells were more resistant than nonmelanized yeast cells to chemically generated NO, ROS, hypochlorite and $\mathrm{H}_{2} \mathrm{O}_{2}$, in vitro. Phagocytosis of melanized yeast cells was virtually abolished when mannan, $N$-acetyl glucosamine and anti-CD18 antibody were added together in this system. Intratracheal infection of BALB/c mice, with melanized yeast cells, resulted in higher lung colony forming units, when compared to nonmelanized yeast cells. Therefore, melanin is a virulence factor of $\mathrm{P}$. brasiliensis.

Key words: melanin - P. brasiliensis - antimicrobial oxidants - anti-CD18 antibody

The dimorphic fungus Paracoccidioides brasiliensis is the etiologic agent of paracoccidioidomycosis (PCM). PCM is a chronic, granulomatous disease, geographically limited to Latin America. The disease is acquired by inhalation of fungal conidia, presumably from the soil and likely on routes of armadillo roving (San-Blas et al. 1993, Restrepo et al. 2000, Bagagli et al. 2006).

The ability of microorganisms to produce melanin pigment has been associated with virulence and pathogenicity in their respective animal or plant hosts (Nosanchuk \& Casadevall 2003). In general, melanins are hydrophobic, negatively charged macromolecules, formed by oxidative polymerization of phenolic or indolic compounds. In fungi, there are two important types of melanin, DHNmelanin, named after the biosynthetic intermediate, 1, 8-dihydroxynaphthalene and DOPA-melanin, named after L-3, 4-dihydroxyphenylalamine. Both types of melanin have been implicated in pathogenesis (Langfelder et al. 2003). The production of melanin in P. brasiliensis, Cryptococcus neoformans, Histoplasma capsulatum and Coccidioides posadasii requires the presence of an

Financial support: CPT and LRT were supported by Fapesp (07/075882, 06/50634-2 and 05/02776-0) and CNPq (470636/2007-6). CPT and LRT are research fellows of the CNPq. JDN is supported in part by NIH (AI056070-01A2).

+Corresponding author: taborda@usp.br

Received 5 July 2008

Accepted 4 March 2009 exogenous substrate, in the form of $o$-diphenolic or $p$ diphenolic compounds, such as L-DOPA (Nosanchuk \& Casadevall 2003, Nosanchuk et al. 2007).

Previous reports have described the mechanisms by which melanin is able to protect fungal cells from the host immune system. The following species were investigated: C. neoformans (Nosanchuk et al. 2000, Rosas et al. 2000), Sporothrix schenckii (Romero-Martinez et al. 2000), P. brasiliensis (Gomez et al. 2001, da Silva et al. 2006), Fonsecaea pedrosoi (Alviano et al. 2004), Aspergillus fumigatus (Youngchim et al. 2004) and C. posadasii (Nosanchuk et al. 2007). Generally, a cellular immune response appears to be the most effective defence mechanism against both experimental and human PCM (Calich et al. 1994, Marques Mello et al. 2002, Batista et al. 2005). Macrophages have a pivotal role in innate immunity, due to their ability to phagocytose and kill microorganisms, as well as to attract and activate other cell types, which are critical to the immune response (Linehan et al. 2000).

Activated macrophages produce a number of substances that are potentially harmful to foreign cells. Reactive oxygen species (ROS), generated by phagocytes, are principally important in host defence, because they can kill invading pathogens (Murray \& Cohn 1980, Test $\&$ Weiss 1986). Nitric oxide (NO) is generated from Larginine by the inducible isoform of NO synthase, iNOS. The oxygen-dependent mechanisms involve a series of reactions, starting with the production of superoxide anion $\left(\mathrm{O}_{2}^{-}\right)$, which gives rise to hydrogen peroxide $\left(\mathrm{H}_{2} \mathrm{O}_{2}\right)$. The heme enzyme, myeloperoxidase, catalyzes the conversion of $\mathrm{H}_{2} \mathrm{O}_{2}$ and halides $\left(\mathrm{Cl}^{-}, \mathrm{I}^{-}\right)$, to hypohalites, such as hypochlorite $\left(\mathrm{ClO}^{-}\right)$and chloramines, which exert potent antifungal activities (Babior 2000). Both reactions 
of $\mathrm{H}_{2} \mathrm{O}_{2}$ with superoxide and hypohalites give rise to the highly reactive, ${ }^{1} \mathrm{O}_{2}$ singlet oxygen.

Given the potential role of melanin in P. brasiliensis virulence, we investigated the effect that exposure to chemically generated ROS and reactive nitrogen species (RNS) had on fungal cells. In addition, we examined the inhibitory involvement of carbohydrates and anti-CD18 antibody, of yeast cell phagocytosis by macrophages. Finally, we analyzed infection of BALB/c mice with melanized yeast cells.

\section{MATERIALS AND METHODS}

BALB/c mice were bred at the animal facility of the Institute of Biomedical Sciences, University of São Paulo, under pathogen-free conditions. The care of animals was conducted according to the procedures of the local Ethical Committee and international rules. Virulent $P$. brasiliensis 18 ( $\mathrm{Pb} 18)$ growth, with or without L-DOPA and the production of melanin ghosts, was carried out according to previously described methods (da Silva et al. 2006). Antibodies against melanin were obtained by immunization of mice with melanin ghosts as previously described (Nosanchuk et al. 1998). Fresh BALB/c serum was used as complement source and when needed, was heat inactivated. Phagocytosis assays, with macrophage-like J774.16 cell lineage and MH-S cells, as well as primary peritoneal and alveolar macrophages, were performed as previously described (da Silva et al. 2006). The inhibitory effect on yeast phagocytosis by $\mathrm{N}$-acetylglucosamine (Sigma, StLouis, MO) was tested at $8 \mathrm{mg} / \mathrm{mL}$, that by mannan (Sigma, StLouis, MO) at $10 \mathrm{mg}$ and by laminarin (Sigma, StLouis, MO) at $100 \mu \mathrm{g} / \mathrm{mL}$. Monoclonal antibody against CD18 (BD-Pharmingen, San Diego, CA) was used at $10 \mu \mathrm{g} / \mathrm{mL}$. NO production was quantified in the supernatants, after the phagocytosis assay, by the accumulation of nitrite, using Griess' reagent. NO and reactive nitrogen intermediates were generated in a solution containing 25 $\mathrm{mM}$ succinic acid (Sigma, St Louis, $\mathrm{MO})(\mathrm{pH} 4.17)$ and 0.5 $\mathrm{mM} \mathrm{NaNO}$ (Alspaugh \& Granger 1991). The oxidative system was generated by using ferric ammonium sulfate (Sigma, St Louis, MO), $\mathrm{H}_{2} \mathrm{O}_{2}$ (Sigma, St Louis, MO) and epinephrine bitartrate (Sigma, St Louis, MO) (Polacheck et al. 1990, Wang \& Casadevall 1994). A chloride-free sodium hypochlorite generating system was developed, as described by Hazen et al. (1996), and modified from previously described methods (Thomas et al. 1986). Hydrogen peroxide activity was determined as described by Lee at al. (1995). The count of fungal cell viability, expressed as colony forming units (CFU), was used to determine the survival rate of melanized and nonmelanized yeast when exposed to oxidants. Intratracheal infection of BALB/c mice with $3 \times 10^{5}$ yeast cells of $P$. brasiliensis, melanized and nonmelanized, was performed as previously described (Buissa-filho et al. 2008). For statistical analysis, the GraphPad Prism5 software was utilized. Results are expressed as means \pm SD of animal groups or experiments and the nonparametric Tukey test was used. Additionally, the Unpaired Student's $t$ test, with Welch's correction (two-tailed), was used for comparison of two groups when the data met the assumptions of the $t$ tests. A $p$ value of $<0.05$ indicates statistical significance.

\section{RESULTS}

Following melanization of yeast cells of $P$. brasiliensis and phagocytosis assays, all of the controls showed expected results based on our previously published work (da Silva et al. 2006). Therefore, we analyzed the inhibitory effects of carbohydrates and antibody to CD18 on the phagocytosis of melanized and nonmelanized yeast cells, by macrophage-like J774.16 and MH-S cells and by primary peritoneal and alveolar macrophages. Macrophages were treated with mannan, laminarin, $N$ acetyl-D-glucosamine and with monoclonal antibody to CD18, either individually or in combination. All of the treatments tested significantly reduced the phagocytosis of nonmelanized cells by macrophage-like J774.16 (Fig. 1A) and by MH-S cells (Fig. 1B). However, only individual treatments of mannan and laminarin significantly reduced the phagocytosis of melanized cells (Fig. 1A, B). When mannan and $\mathrm{N}$-acetylglucosamine were mixed in the presence of anti-CD18 mAb, phagocytosis was virtually abolished in both J774.16 (Fig. 1A) and MH-S cells (Fig. 1B). Similar results were obtained with primary peritoneal and alveolar macrophages (data not shown).
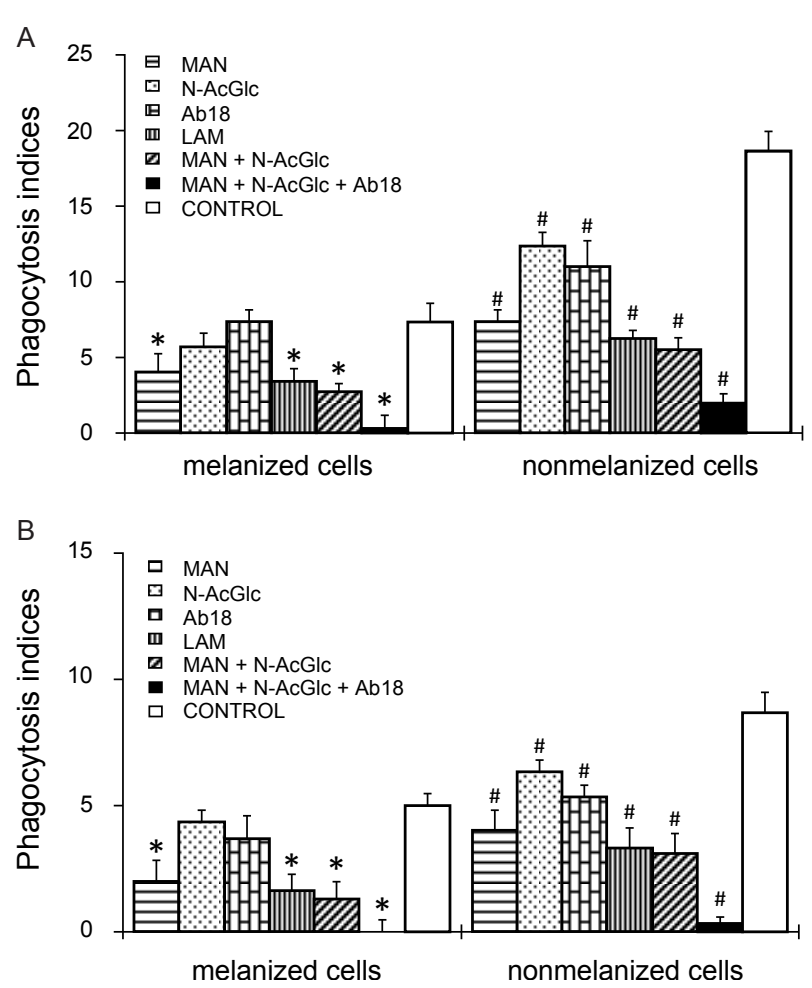

Fig. 1: inhibition assays. Inhibition by sugars and $\mathrm{mAb}$ to CD18 of phagocytosis by J774.16 cells of Paracoccidioides brasiliensis yeast cells grown with L-DOPA and without L-DOPA (A) as well as by MH-S cells (B). Ab18: anti-CD18 mAb; control: no sugar and antibody added; LAM: laminarin; MAN: mannan; N-AcGlc: N-acetyl-D-glucosamine. The bars indicate means of three measurements with standard deviations; asterisks means: statistically significant difference $(\mathrm{p}<0.05)$ relative to the control with melanized cells; \#: statistically significant difference $(p<0.05)$ compared with the control of nonmelanized cells. Experiments were repeated at least three times with similar results. 
Addition of complement and/or antibody against melanin was shown to increase macrophage uptake of opsonized yeast cells (da Silva et al. 2006). In this work, we measured the NO formed by J774.16 and MH-S cells, as nitrite, in response to the presence of both complement and antibody-opsonized, or nonopsonized, melanized yeast cells of $P$. brasiliensis. Nitrite was quantified after 6, 12 and $24 \mathrm{~h}$. Complement-opsonized melanized yeasts, when phagocytosed, induced a slight increase in the production of nitrite as compared to nonopsonized cells. Melanized yeasts opsonized with antibody against melanin showed a statistically significant increase in nitrite concentration after $12 \mathrm{~h}(14.5 \pm 0.09 \mu \mathrm{M})$ and $24 \mathrm{~h}$ $(16.6 \pm 0.05 \mu \mathrm{M})$ in $\mathrm{J} 774.16$ cells and after $24 \mathrm{~h}(13.7 \pm$ $0.4 \mu \mathrm{M})$ in MH-S cells, when compared to nonopsonized yeasts [J774.16 after $12 \mathrm{~h}(12.3 \pm 0.4 \mu \mathrm{M})$ and $24 \mathrm{~h}(13.1$ $\pm 0.06 \mu \mathrm{M})$ and $\mathrm{MH}-\mathrm{S}$ after $12 \mathrm{~h}(10.9 \pm 0.3 \mu \mathrm{M})]$.

In order to observe the effect of antimicrobial oxidants, generated in vitro, on the viability of $P$. brasiliensis yeast cells, melanized and nonmelanized cells were first exposed to chemically generated NO. The results demonstrate that growth of both melanized and nonmelanized yeasts of $P$. brasiliensis was inhibited, but that melanized cells were less susceptible to no than nonmelanized cells (Fig. 2). When melanized and nonmelanized yeasts were incubated hourly, from 1-6 h, in an oxidative system containing epinephrine, hydrogen peroxide and ferric ammonium sulfate, the melanized cells were also less susceptible to these oxidants than nonmelanized cells were after different times of exposure to oxygen radicals (Fig. 2). The exposure to a chloride-free, sodium hypochlorite generating system,
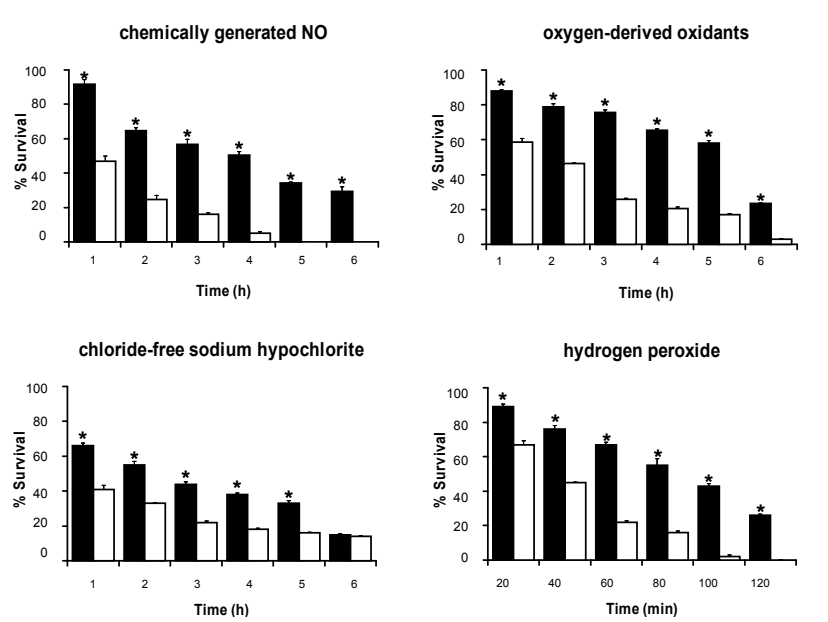

Fig. 2: killing assays. Killing of 15-day-old cultures of Paracoccidioides brasiliensis grown with and without L-DOPA and exposed to chemically generated nitric oxide (NO), oxygen-derived oxidants generated in the epinephrine oxidative system, chloride-free sodium hypochlorite and hydrogen peroxide. Treated yeasts at the times indicated were plated on solid BHI in triplicate to monitor cell viability. The bars denote the average of three measurements and the error bars are standard deviations. $\square$ : melanized yeast cells; $\square$ : nonmelanized yeast cells; asterisks means: statistically significant difference $(\mathrm{p}<$ 0.05 ) relative to nonmelanized cells. showed that survival of melanized cells was significantly higher than that of nonmelanized cells, except after 6 h, when no differences were observed (Fig. 2). Finally, we demonstrated that melanized cells, pretreated with $\mathrm{H}_{2} \mathrm{O}_{2}$, were more resistant to killing than nonmelanized yeasts of $P$. brasiliensis (Fig. 2).

In order to prove that melanin can provide an efficient virulence mechanism for the fungus, BALB/c mice were challenged by intratracheal inoculation of melanized, or nonmelanized yeasts, of the virulent strain Pb18. Thirty and sixty days after being infected, mice were killed and lung CFUs were quantified. The CFU per g/tissue, in the group of melanized yeast-infected mice, was higher after 30 days $(30,000 \pm 400)$ and 60 days $(28,000 \pm 700)$ of infection, than in the nonmelanized yeast infected mice after 30 days $(19,000 \pm 800)$ and 60 days $(14,000 \pm 1,200)$.

\section{DISCUSSION}

Little is known about the relationship between melanin and the immune system. Macrophages can be activated by different stimuli, can express heterogeneous markers and can display distant biological functions (Mosser 2003). Some authors have shown that melanins affect macrophages and reduce production of proinflammatory cytokines (Taborda et al. 2008). We have previously shown that melanization interferes with macrophage uptake of fungal cells and that most melanized cells remain adhered to the macrophages, even after $12 \mathrm{~h}$, as quantified by the lateral binding indices (da Silva et al. 2006).

Macrophages can uptake microorganisms by receptors that recognize carbohydrates, such as $\beta$-glucan receptors, CR3 and the mannose/fucose receptor, as well as other structures, such as antibodies, complement by Fc receptors and CR1 (Linehan et al. 2000). The involvement of CR3 and mannose receptor in the uptake of opsonized and nonopsonized $P$. brasiliensis conidia was documented (Jimenez et al. 2006). We have shown previously that mannan can partially inhibit phagocytosis of P. brasiliensis yeasts (da Silva et al. 2006). In this work, we demonstrate that, in addition to mannan, laminarin, $\mathrm{N}$-acetylglucosamine and anti-CD18 mAb also affected phagocytosis of fungal cells. The most impressive result was obtained with the association of mannan, $\mathrm{N}$-acetylglucosamine and anti-CD18 mAb, which virtually abolished the internalization of melanized yeasts and was the most effective inhibitor of nonmelanized yeast phagocytosis. The anti-CD18 mAb alone did not significantly alter the phagocytosis of melanized yeast cells, which suggests that cooperation with other receptors is important.

Once the microorganisms are internalized by macrophages, secondary responses are activated. NO produced in activated macrophages is cytotoxic to $P$. brasiliensis (Gonzalez et al. 2007). Our results show that melanized fungal cells are more resistant to both ROS and RNS. In another fungal system, melanized cells of C. neoformans proved to be less susceptible to killing by nitrogen-derived radicals (Wang \& Casadevall 1994). Wang et al. (1995) demonstrated that even small amounts of melanin protected $C$. neoformans cells from RNS and that melanized cells were also less susceptible to killing by ROS. Our results suggest that melanized $P$. 
brasiliensis can use the black pigment to quench ROS and to protect yeasts from macrophage killing. Oxygenradicals formed in the epinephrine oxidative system are equivalent to products of the oxidative burst in immune effector cells of the immune system (Klebanoff 1980).

The chloride-free, sodium hypochlorite generating system decreased the survival of melanotic cells, below that of nonmelanotic cells, of P. brasiliensis. Accordingly, melanized $C$. neoformans yeast cells were also shown to be less susceptible to killing by hypochlorite and permanganate (Jacobson \& Tinnell 1993). In addition, melanized yeast cells of $P$. brasiliensis were more resistant to killing by hydrogen peroxide. This result confirms a previous study which showed that melanized cells of $S$. schenckii were also less susceptible to killing by hydrogen peroxide (Romero-Martinez et al. 2000). As mentioned above, melanized $P$. brasiliensis yeast cells are more resistant to in vitro generated ROS and RNS. To verify the resistance of melanized $P$. brasiliensis yeast cells in vivo, mice were infected intratracheally with melanized and nonmelanized yeast cells. The infection resulted in higher lung CFU by melanized yeasts, compared to infection with nonmelanized cells, most likely due to their reduced internalization by macrophages and their greater resistance to intracellular death.

In conclusion, we have shown that melanin plays an important role in the pathogenesis of $P$. brasiliensis by protecting fungal cells from microbicidal RNS and ROS. The increased resistance of melanized yeasts of $P$. brasiliensis involves a combination of reduced phagocytosis and protection against oxidative radicals produced in the host effector cells.

\section{REFERENCES}

Alspaugh JA, Granger DL 1991. Inhibition of Cryptococcus neoformans replication by nitrogen oxides supports the role of these molecules as effectors of macrophage-mediated cytostasis. Infect Immun 59: 2291-2296.

Alviano DS, Franzen AJ, Travassos LR, Holandino C, Rozental S, Ejzemberg R, Alviano CS, Rodrigues ML 2004. Melanin from Fonsecaea pedrosoi induces production of human antifungal antibodies and enhances the antimicrobial efficacy of phagocytes. Infect Immun 72: 229-237.

Babior BM 2000. Phagocytes and oxidative stress. Am J Med 109: 33-44.

Bagagli E, Bosco SM, Theodoro RC, Franco M 2006. Phylogenetic and evolutionary aspects of Paracoccidioides brasiliensis reveal a long coexistence with animal hosts that explain several biological features of the pathogen. Infect Genet Evol 6: 344-351.

Batista AC, Soares CT, Lara VS 2005. Failure of nitric oxide production by macrophages and decrease in $\mathrm{CD} 4^{+} \mathrm{T}$ cells in oral paracoccidioidomycosis: possible mechanisms that permit local fungal multiplication. Rev Inst Med Trop Sao Paulo 47: 267-273.

Buissa-Filho R, Puccia R, Marques AF, Pinto FA, Muñoz JE, Nosanchuck JD, Travassos LR, Taborda CP 2008. The monoclonal antibody against the major diagnostic antigen of Paracoccidioides brasiliensis mediates immune protection in infected $\mathrm{BALB} / \mathrm{c}$ mice challenged intratracheally with the fungus. Infect Immun 76: 3321-3328.

Calich VL, Singer-Vermes LM, Russo M, Vaz CA, Burger E 1994. Immunogenetics. In M Franco, CS Lacaz, A Restrepo, G del Negro, Paracoccidioidomycosis, CRC Press, Flórida, p. 151-173. da Silva MB, Marques AF, Nosanchuk JD, Casadevall A, Travassos LR, Taborda CP 2006. Melanin in the dimorphic fungal pathogen Paracoccidioides brasiliensis: effects on phagocytosis, intracellular resistance and drug susceptibility. Microbes Infect 8: 197-205.

Gomez BL, Nosanchuk JD, Diez S, Youngchim S, Aisen P, Cano LE, Restrepo A, Casadevall A, Hamilton AJ 2001. Detection of melanin-like pigments in the dimorphic fungal pathogen Paracoccidioides brasiliensis in vitro and during infection. Infect Immun 69: 5760-5767.

Gonzalez A, Restrepo A, Cano LE 2007. Role of iron in the nitric oxide-mediated fungicidal mechanism of IFN-gamma-activated murine macrophages against Paracoccidioides brasiliensis conidia. Rev Inst Med Trop Sao Paulo 49: 11-16.

Hazen SL, Hsu FF, Mueller DM, Crowley JR, Heinecke JW 1996. Human neutrophils employ chlorine gas as an oxidant during phagocytosis. J Clin Invest 98: 1283-1289.

Jacobson ES, Tinnell SB 1993. Antioxidant function of fungal melanin. J Bacteriol 175: 7102-7104.

Jimenez MDP, Restrepo A, Radzioch D, Cano LE, Garcia LF 2006. Importance of complement 3 and mannose receptors in phagocytosis of Paracoccidioides brasiliensis conidia by Nramp1 congenic macrophages lines. FEMS Immunol Med Microbiol 47: 56-66.

Klebanoff SJ 1980. Oxygen metabolism and the toxic properties of phagocytes. Ann Intern Med 93: 480-489.

Langfelder K, Streibel M, Jahn B, Haase G, Brakhage AA 2003. Biosynthesis of fungal melanins and their importance for human pathogenic fungi. Fungal Genet Biol 38: 143-158.

Lee J, Dawes IW, Roe JH 1995. Adaptive response of Schizosaccharomyces pombe to hydrogen peroxide and menadione. Microbiology 141 (Pt 12): 3127-3132.

Linehan SA, Martinez-Pomares L, Gordon S 2000. Macrophage lectins in host defence. Microbes Infect 2: 279-288.

Marques Mello L, Silva-Vergara ML, Rodrigues V Jr 2002. Patients with active infection with Paracoccidioides brasiliensis present a Th2 immune response characterized by high Interleukin-4 and Interleukin-5 production. Hum Immunol 63: 149-154.

Mosser DM 2003. The many faces of macrophages activation. J Leuk Biol 73: 209-212.

Murray HW, Cohn ZA 1980. Macrophage oxygen-dependent antimicrobial activity. III. Enhanced oxidative metabolism as an expression of macrophage activation. J Exp Med 152: 1596-1609.

Nosanchuk JD, Casadevall A 2003. The contribution of melanin to microbial pathogenesis. Cell Microbiol 5: 203-223.

Nosanchuk JD, Rosas AL, Casadevall A 1998. The antibody response to fungal melanin in mice. J Immunol 160: 6026-6031.

Nosanchuk JD, Rosas AL, Lee SC, Casadevall A 2000. Melanization of Cryptococcus neoformans in human brain tissue. Lancet 355 : 2049-2050.

Nosanchuk JD, Yu JJ, Hung CY, Casadevall A, Cole GT 2007. Coccidioides posadasii produces melanin in vitro and during infection. Fungal Genet Biol 44: 517-520.

Polacheck I, Platt Y, Aronovitch J 1990. Catecholamines and virulence of Cryptococcus neoformans. Infect Immun 58: 2919-2922.

Restrepo A, Baumgardner DJ, Bagagli E, Cooper CR, Jr, McGinnis MR, Lazera MS, Barbosa FH, Bosco SM, Camargo ZP, Coelho KI, Fortes ST, Franco M, Montenegro MR, Sano A,Wanke B 2000. Clues to the presence of pathogenic fungi in certain environments. Med Mycol 38 (Suppl. 1): 67-77. 
Romero-Martinez R, Wheeler M, Guerrero-Plata A, Rico G, Torres-Guerrero $\mathrm{H}$ 2000. Biosynthesis and functions of melanin in Sporothrix schenckii. Infect Immun 68: 3696-3703.

Rosas AL, Nosanchuk JD, Feldmesser M, Cox GM, McDade HC, Casadevall A 2000. Synthesis of polymerized melanin by Cryptococcus neoformans in infected rodents. Infect Immun 68: $2845-2853$.

San-Blas G, Marino L, San-Blas F, Apitz-Castro R 1993. Effect of ajoene on dimorphism of Paracoccidioides brasiliensis. J Med Vet Mycol 31: 133-141

Taborda CP, da Silva MB, Nosanchuk JD, Travassos LR 2008. Melanin as a virulence factor of Paracoccidioides brasiliensis and other dimporphic pathogenic fungi: a minireview. Mycopathologia 165: 331-339.
Test ST, Weiss SJ 1986. The generation and utilization of chlorinated oxidants by human neutrophils. Adv Free Rad Biol Med 2: 91-116.

Thomas EL, Grisham MB, Jefferson MM 1986. Preparation and characterization of chloramines. Methods Enzymol 132: 569-585.

Wang Y, Aisen P, Casadevall A 1995. Cryptococcus neoformans melanin and virulence: mechanism of action. Infect Immun 63: 3131-3136.

Wang Y, Casadevall A 1994. Susceptibility of melanized and nonmelanized Cryptococcus neoformans to nitrogen- and oxygenderived oxidants. Infect Immun 62: 3004-3007.

Youngchim S, Morris-Jones R, Hay RJ, Hamilton AJ 2004. Production of melanin by Aspergillus fumigatus. J Med Microbiol 53: 175-181. 